\title{
Effect of Nanostructured and Open-Porous Particle Morphology on Electrode Processing and Electrochemical Performance of Li-lon Batteries
}

\author{
Marcus Müller,* Luca Schneider, Nicole Bohn, Joachim R. Binder, and Werner Bauer
}

Cite This: ACS Appl. Energy Mater. 2021, 4, 1993-2003

Read Online

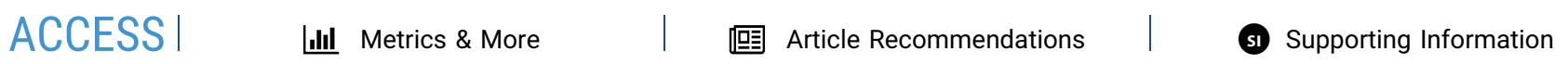

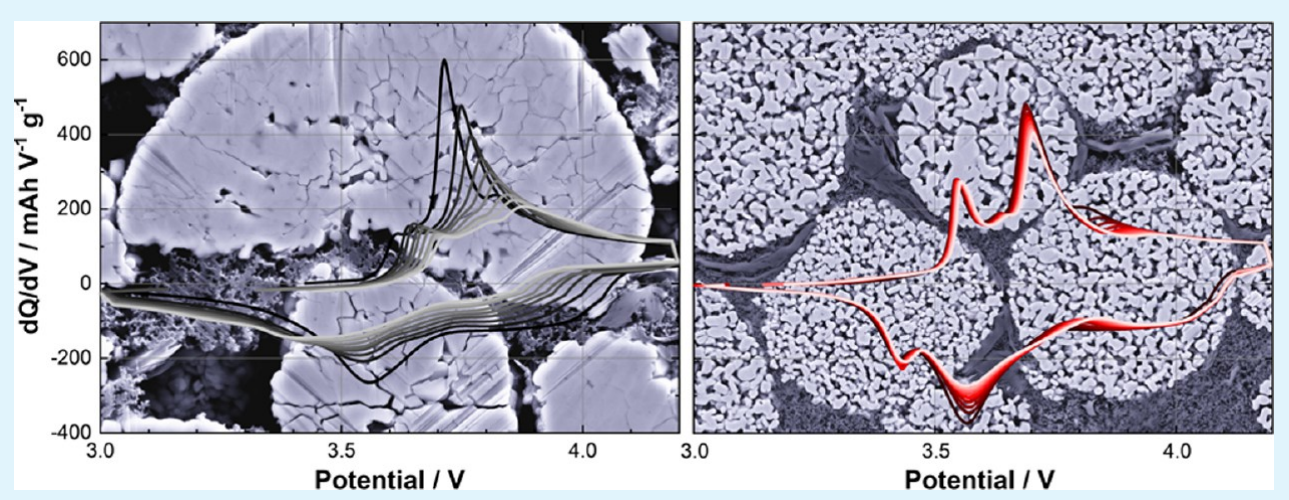

ABSTRACT: A nanostructured, porous NCM cathode material is investigated regarding its behavior during electrode processing and electrochemical performance. The results are related to the densely packed NCM original material from which the nanostructure has been derived. Chemical composition and structural parameters are not affected by the nanostructuring process; changes are limited to the particle morphology in terms of primary particle size, specific surface area, and porosity. Electrodes containing a porous NCM material deliver lower adhesion strength values when adding identical amounts of PVDF binder. Increasing the binder fraction from four to six parts increases also the adhesion strength to an acceptable level without deteriorating the cell capacity. Despite initially high electrode porosities of $65-70 \%$, electrodes with nanostructured NCM are capable of withstanding calendering to $40 \%$ porosity without destroying the porous particles. Full-cell tests with $50 \mathrm{mAh}$ pouch cells and graphite anodes reveal substantially improved C-rate capabilities for the nanostructured material in relation to the commercial original NCM. The advantage increases with increasing C-rate and corresponds to shorter diffusion pathways in nanostructured NCM. Remarkably, even at low C-rates $(\mathrm{C} / 20)$ where diffusion effects are considered secondary, porous NCM lies ahead of the original material. This can be explained by the higher surface area and thereby enlarged interface to the electrolyte, which eases delithiation. Long-term cycling up to 1100 cycles displayed further benefits for the nanostructured active material as one of the most prominent degradation factors, that is, crack formation and particle fragmentation, does not occur throughout the complete cycling procedure-in contrast to the bulk particles of original NCM.

KEYWORDS: Li-ion battery, NCM, particle morphology, pouch cells, and capacity fading

\section{INTRODUCTION}

State-of-the art lithium-ion batteries widely use layered-oxides with transition metals $\mathrm{Ni}, \mathrm{Co}$, and $\mathrm{Mn}$ as active materials on the cathode side. ${ }^{1,2}$ These oxides are commercially supplied as dense, compact, and equiaxed particles in the size range of 5$10 \mu \mathrm{m}$. The main advantage of such a morphology lies in a high electrode packing density facilitating high energy densities. Inactive components including conductive additives and binders are minimized. Owing to relatively coarse particles, slurries can be prepared with high solid loadings, which is favorable for the coating process (less drying-shrinkage and stresses and low residual porosity).
On the other hand, particles in the micron-range imply longer diffusion pathways for $\mathrm{Li}$ ions and thereby raise limitations for rate capability and power density. Furthermore, stresses that occur during cycling accumulate to higher levels in larger particles. ${ }^{3}$ Because of significant lattice changes upon

Received: December 22, 2020

Accepted: January 28, 2021

Published: February 9, 2021 
charging and discharging, cracks evolve along the grain boundaries (intergranular crack formation). As a consequence, ionic connectivity and electronic connectivity of the grains degrade, ${ }^{4}$ representing one of the major factors for loss of capacitance and cell degradation. ${ }^{5-11}$

Active materials with intrinsic low electrical conductivity such as lithium iron phosphate therefore are employed as nanoscaled particles. Increasing the surface-to-volume ratio enlarges the contact area to conductive additives such as carbon black, and at the same time, Li-exchange is improved. However, higher particle surface areas and an increased demand for carbon black imply higher amounts of binder to deliver sufficient adhesion strength. This combination aggravates the preparation of slurries with high solid loading and electrodes with competitive fractions of active materials; the achievable energy densities are correspondingly lower.

An alternative approach aggregates fine-scaled particles into secondary particles while preserving sufficient porosity. Thereby, it is possible to combine the advantages of both worlds, namely, an easy processability of micron-sized particles and short diffusion pathways and reduced stress development attributed to nanosized particles. A detailed investigation of the effects of NCM111 particle morphology, especially porosity, on the electrochemical performance was reported by Cabelguen et al. ${ }^{12}$ For open-porous secondary particles consisting of cuboid primary particles (in contrast to flakeshaped), they state substantial benefits because of reduced solid-state diffusion and increased Li-insertion sites. Chen et al. ${ }^{13}$ found clearly improved rate capabilities and capacity retention for hierarchically porous NCM111 particles with uniform size distribution around $3 \mu \mathrm{m}$ and a high specific surface area (SSA) $\left(20 \mathrm{~m}^{2} / \mathrm{g}\right) . \mathrm{Li}$ et al. ${ }^{14}$ synthesized porous NCM111 microspheres with diameters below $1.5 \mu \mathrm{m}$ and a SSA of $52 \mathrm{~m}^{2} / \mathrm{g}$. Lin et al. ${ }^{15}$ presented a hierarchically structured NCM442 cathode material (synthesized by spray pyrolysis and subsequent calcination at $850{ }^{\circ} \mathrm{C}$ ), consisting of nanosized primary particles $(50-200 \mathrm{~nm})$ that form hollow spheres of $5-20 \mu \mathrm{m}$ as secondary particles. They observed in half-cells higher discharge capacities and better capacity retention compared to the material obtained by the coprecipitation method. Similar results are also described by Yang et al. ${ }^{16}$ and Oljaca et al. ${ }^{17}$ with a hierarchically structured NCM111 material. Superior rate capabilities are ascribed to a shorter diffusion length in the solid phase and an increased electrochemically active surface area, providing an appropriate contact area between the electrode and electrolyte.

In studies where material synthesis is the focus, electrochemical tests often are based on half-cells ( $\mathrm{Li}$ metal anode). Furthermore, electrode compositions are chosen, which are far away from practical application (typically $10 \mathrm{wt} \%$ carbon black, 10 wt \% PVDF binder, and 80 wt \% active material). It is a central aspect of the present investigation to assess the potential of the porous, nanostructured cathode material under more relevant conditions. In a previous publication, we could demonstrate the general advantages of nanostructured NCM111 in terms of capacity and aging behavior also for full-cells (pouch-geometry and $50 \times 50 \mathrm{~mm}^{2}$ cathodes). ${ }^{18}$ However, another outcome of these investigations was that the standard electrode processing, which is optimized to conventional particle morphologies, has to be adapted to the modified particle microstructure. As described by Bockholt et al. ${ }^{19}$ the influence of processing on electrode properties and indirectly on electrochemical performance is complex. The present work therefore aims at identifying the major morphological effects on the electrode processing and the resulting electrode properties, which includes adhesion strength, resistivity, and porosity. Thereafter the electrode performance is assessed in full-cell tests (pouch cells) in regard to C-rate capability, capacity retention, and degradation behavior.

\section{EXPERIMENTAL SECTION}

\subsection{Materials Processing and Characterization.} $\mathrm{LiNi}_{0.33} \mathrm{Co}_{0.33} \mathrm{Mn}_{0.33} \mathrm{O}_{2}$ - often abbreviated as $\mathrm{NCM} 111$ - was used as a starting and reference material for the investigation (NM-3100, Toda Kogyo Corp., hereafter, NCM-O). By further processing, the powder was modified to obtain nanostructured and porous secondary particles (hereafter, NCM-P). In a first step, the original Toda NM3100 was milled and dispersed in distilled water for $3.5 \mathrm{~h}$ using an agitator bead mill (LabStar LS1, Netzsch) with yttria-stabilized zirconia beads (diameter: $0.2 \mathrm{~mm}$ ). Thereby, the particle size of original NCM-O was reduced to $200 \mathrm{~nm}$. The suspension contained $22 \mathrm{wt} \%$ NCM powder and as a dispersant 1.6 wt \% Darvan 821A (ammonium polyacrylate, Vanderbilt Minerals). After milling, $0.25 \mathrm{wt}$ $\%$ polyethylene glycol (Sigma-Aldrich) was added, and the suspension was spray-dried (MobileMinor, GEA Niro). The spray-dried NCM granules were calcined at $850{ }^{\circ} \mathrm{C}$ for $5 \mathrm{~h}$ (heating rate $5 \mathrm{~K} / \mathrm{min}$ ) under air using alumina crucibles.

Starting materials and the processed powders were characterized as follows. The (secondary) particle size distribution was measured by laser diffraction (Horiba LA950, Retsch Technology) after dispersing in 2-propanol. The Brunauer-Emmett-Teller (BET) SSA was detected via the nitrogen adsorption method (Gemini VII 2390, Micromeritics). The density of the active materials was measured by helium pycnometry (AccuPyc 1330, Porotec). Hg-intrusion porosimetry (Pascal 440 Evo, Thermo Scientific) was used to characterize the porous cathode material as well as the coated electrodes. The latter were measured including the aluminum current collector foil. After the measurement, the samples have been directly inspected to check for the unintended $\mathrm{Al} / \mathrm{Hg}$ reaction (alloying) because of the applied high pressure of $400 \mathrm{MPa}$.

Imaging of the active material and coated electrodes was performed using a field-emission scanning electron microscope (Supra 55, Zeiss). Where required, the samples were cross-sectioned before inspection by ion-beam milling (EM TIC3X, Leica Microsystems) using argon ions and an accelerating voltage of $6 \mathrm{kV}$ at $2.2 \mathrm{~mA}$ gun current. From cross-sections, also the primary particle size distribution of NCM-O was determined by image analysis of scanning electron microscopy (SEM) micrographs (Image J software). For this purpose, more than 500 primary particles were analyzed by measuring the largest diameter of two boundary points. In the case of NCM-P, the primary particle size was calculated based on the BET SSA, a theoretical density of $4.77 \mathrm{~g} / \mathrm{cm}^{3}$ for NCM and the simplifying assumption of spherical particles.

2.2. Electrode Manufacturing and Cell Tests. For the cathode slurries, the active material (NM-3100, Toda Kogyo Corp.; as received or processed) was mixed with carbon black (C-NERGY Super C65, Imerys Graphite \& Carbon, Bodio, Switzerland), graphite (C-NERGY KS6L, Imerys), and PVDF (Solef 5130, Solvay S.A., Italy) in $N$-methyl-2-pyrrolidone (NMP, Carl Roth) using a dissolver mixer (Dispermat, VMA Getzmann GmbH, Germany) at $2000 \mathrm{rpm}$ for $1 \mathrm{~h}$ ( 5 min degassing under vacuum). In Table 1, the compositions are summarized. When the active material is set to 100 , the other solids amount to 4 , defining this slurry as 444 . By increasing the

\section{Table 1. Composition of Cathode Slurries}

\begin{tabular}{llccccc} 
& \multicolumn{3}{c}{$\begin{array}{c}\text { carbon } \\
\text { black }\end{array}$} & graphite & PVDF & \multicolumn{2}{c}{ solid content } \\
slurry comp. & mass\% & & & & mass\% & Vol \% \\
444 & 89.3 & 3.57 & 3.57 & 3.57 & 50.4 & 20.4 \\
446 & 87.7 & 3.51 & 3.51 & 5.26 & 47.8 & 18.7
\end{tabular}


PVDF content to 6 (446), additional amounts of NMP solvent had to be added to keep the viscosity in the same range (thereby decreasing the solid content). For the preparation of the electrodes, the slurries were cast on aluminum foil $(20 \mu \mathrm{m})$ using a roll-to-roll coater (KTF$\mathrm{S}$, Mathis AG, Switzerland) with a knife coating device and integrated convection-drying stages set to 80 and $120{ }^{\circ} \mathrm{C}$, respectively. The evaporation of the NMP solvent was completed within $10 \mathrm{~min}$. Compaction of the electrodes was performed in a heated calendar (Saueressig GLK 200) at $50{ }^{\circ} \mathrm{C}$.

Graphite anodes were manufactured similarly, but an aqueous processing route was used. SMG-A (Hitachi Chemical, Japan) with an average particle size of about $20 \mu \mathrm{m}$ was used as the active material. The same C65 carbon black as for the cathode formulation was applied for improving binder conductivity. A 2 mass\% solution of carboxymethyl cellulose (sodium-salt, Na-CMC, CRT 2000 PA7, DOW Wolff) in deionized water was used as one binder component. Styrene-butadiene rubber (SBR) supplied as a latex binder with 170 $\mathrm{nm}$ particle size (TRD 2001, JSR Micro) served as the second binder. The SBR was added after slurry homogenization was completed to avoid coagulation of the latex particles as a result of high shear forces. The composition of the solid fraction of the aqueous slurry is summarized in Table 2. Because of the application of water as the

Table 2. Composition of Anode Slurries

\begin{tabular}{ccccccc} 
& graphite & $\begin{array}{c}\text { carbon } \\
\text { black }\end{array}$ & CMC & SBR & \multicolumn{2}{c}{ solid content } \\
mass\% & & & & mass\% & Vol \% \\
aqueous anode & 93.5 & 1.9 & 1.8 & 2.8 & 50.3 & 31.8
\end{tabular}

solvent, the drying temperatures during electrode coating were reduced to 30 and $50{ }^{\circ} \mathrm{C}$, respectively. To preserve an open network for Li-ion diffusion within the graphite, calendering of anodes was carried out only to moderate porosities $(\leq 50 \%)$.

The adhesion strength of cathode layers was determined in a universal testing machine (UTS T-10, Zwick, Germany) via $90^{\circ}$ peel tests, based on DIN EN 28510-1. Electrode stripes (17 mm in width and $60 \mathrm{~mm}$ in length) were fixed on a metal plate by double-sided adhesive tape with the NCM layer facing the tape. After pressing with a defined load of $200 \mathrm{~kg}$ for $2 \mathrm{~s}$, the aluminum foil was stripped from the electrode layer at a constant speed of $600 \mathrm{~mm} / \mathrm{min}$. The averaged force between 20 and $30 \mathrm{~mm}$ distance from the edges is used for strength evaluation. For measuring the electrode resistivity in the uncalendered state and depending on calendering, disks $(\phi 14 \mathrm{~mm})$ were cut from electrode sheets and placed between polished copper cylinders $(\phi 14 \mathrm{~mm})$. A pressure of $6.5 \mathrm{kPa}$ was applied on the cylinders while the through-plane resistance was measured using a milliohm meter in DC mode (RM3544, Hioki E.E. Corp., Japan). For that reason, it is not distinguished between electrical and ionic contributions, and the resistivity corresponds to the total resistance of the electrode.

For electrochemical tests, pouch cells were assembled with a cathode size of $50 \times 50 \mathrm{~mm}^{2}$ (average theoretical cell capacity 45 $\mathrm{mAh}$ ), a ceramic-coated separator foil (Separion, Litarion, Germany), and graphite anodes with $54 \times 54 \mathrm{~mm}^{2}$. The components (electrodes and separator) were dried overnight in a vacuum furnace at $130{ }^{\circ} \mathrm{C}$ and assembled in a dry room at a dew point of below $-50{ }^{\circ} \mathrm{C} .450 \mu \mathrm{L}$ of LP30 (1:1 EC/DMC, $1 \mathrm{M} \mathrm{LiPF}_{6}$ ) from BASF SE was added as the electrolyte for each cell. After assembly, the cells were rested for $20 \mathrm{~h}$ at $40{ }^{\circ} \mathrm{C}$ to facilitate complete wetting of the electrode and separator. Cell tests were performed between $3.0 \mathrm{~V}$ and a cutoff voltage of $4.2 \mathrm{~V}$,
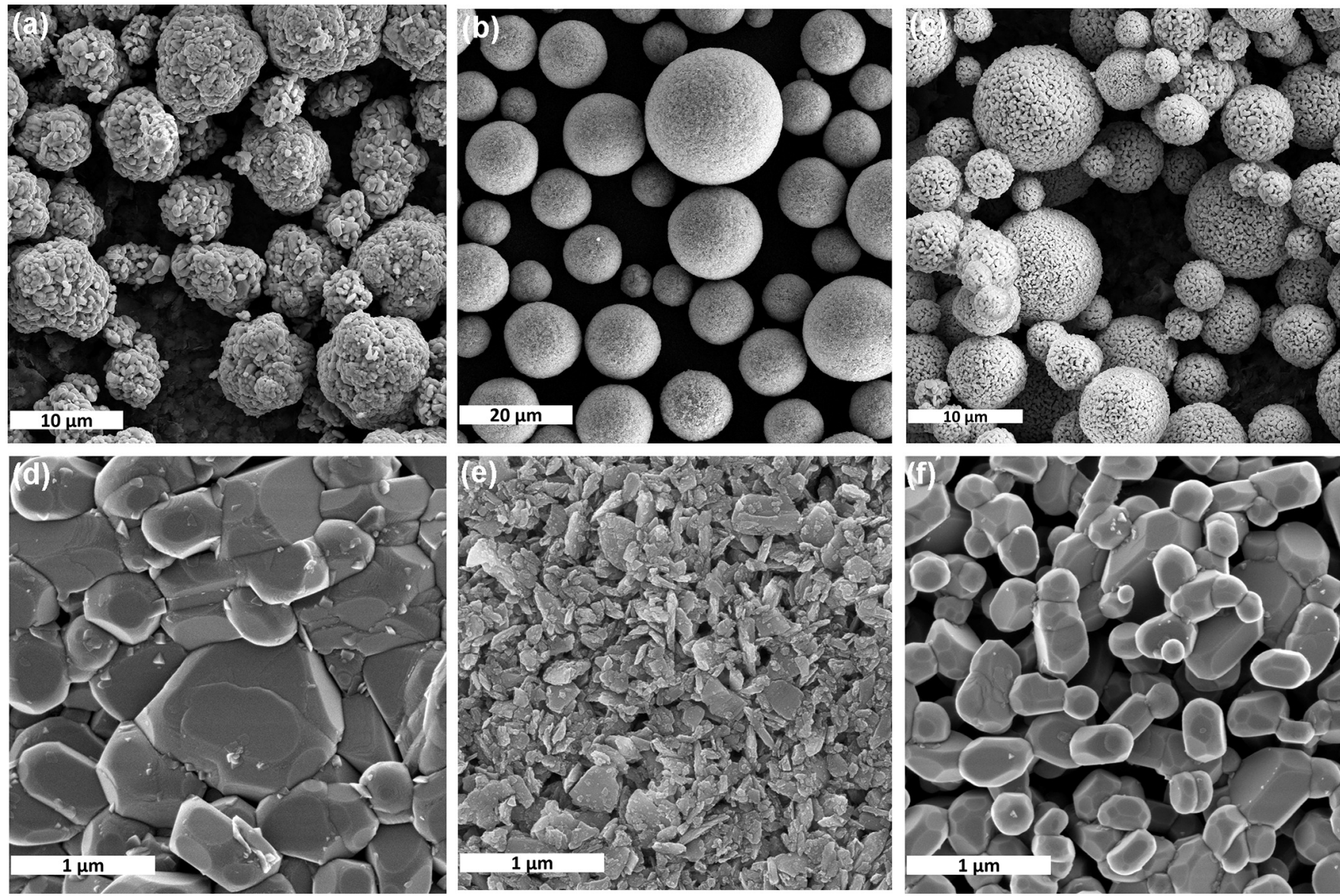

Figure 1. SEM micrographs of as-received NCM111 $(\mathrm{a}+\mathrm{d})$, after milling and spray-drying $(\mathrm{b}+\mathrm{e})$, after calcination at $850{ }^{\circ} \mathrm{C}(\mathrm{c}+\mathrm{f})$. 
Table 3. Properties of NCM111 Powders

\begin{tabular}{|c|c|c|c|c|c|c|c|}
\hline & prim. particle size, $d_{50}$, & sec. particle size, $d_{50}$ & SSA (BET) & density $^{a}$ & tap density ${ }^{b}$ & open por. ${ }^{c}$ & mean pore size ${ }^{c}$ \\
\hline & $\mu \mathrm{m}$ & $\mathrm{Mm}$ & $\mathrm{m}^{2} / \mathrm{g}$ & $\mathrm{g} / \mathrm{cm}^{3}$ & $\mathrm{~g} / \mathrm{cm}^{3}$ & $\%$ & $\mathrm{~nm}$ \\
\hline NCM-O & 0.77 & 7.3 & 0.4 & 4.52 & 2.4 & & \\
\hline NCM-P & 0.35 & 9.9 & 3.3 & 4.70 & 1.4 & 44.2 & 295 \\
\hline
\end{tabular}

at a constant temperature of $23{ }^{\circ} \mathrm{C}$. The C-rates were calculated on the basis of $155 \mathrm{mAh} / \mathrm{g}$ as the reversible capacity for NCM111.

After two initial formation cycles at $0.05 \mathrm{C}$, the rate capability was tested for $0.5 \mathrm{C}, 1 \mathrm{C}, 2 \mathrm{C}$, and $3 \mathrm{C}$ in constant current $(\mathrm{CC})$ mode by symmetrical charging and discharging and 10 cycles for each $\mathrm{C}$-rate. After $3 \mathrm{C}$, cells were cycled again at $0.5 \mathrm{C}$ (10 cycles) and 1C (50 cycles) to see, if irreversible capacity losses had appeared. For testing the capacity retention, cycling was continued with selected cells in 2C charge (constant current-constant voltage $(\mathrm{CCCV})$ charge to a $0.05 \mathrm{C}$ current limit) and $3 \mathrm{C}$ discharge rate. Additional 10 cycles at $1 \mathrm{C}(\mathrm{CC})$ separate blocks of 100 cycles of $2 \mathrm{C} / 3 \mathrm{C}$ to enable the calculation of incremental capacity (IC) curves regularly.

\section{RESULTS AND DISCUSSION}

3.1. Material Properties. To discuss the effect of a modified particle morphology on electrochemical behavior, it was necessary to check, if changes of chemical composition or of structural parameters, induced by intensive material processing, may also contribute to performance changes. However, a comparison of the X-ray diffraction (XRD) patterns of both materials delivered no indication for structural changes because of the processing of the original material (see Supporting Information Figure S1). Chemical analysis by inductively coupled plasma-optical emission spectroscopy (ICP-OES) of the as-received powder and the processed NCM confirmed a composition very close to the denoted 111 ratio of $\mathrm{Ni}, \mathrm{Co}$, and $\mathrm{Mn}$ (see Supporting Information Table $\mathrm{S} 1)$. Again, no changes in the chemical composition could be detected between NCM-O and NCM-P. This observation was somewhat surprising as we expected that intensive milling in water would leach out at least measurable amounts of $\mathrm{Li}$, as often observed and described in the literature. ${ }^{20-23}$ It is therefore reasonable to conclude that by spray-drying of the entire milling-suspension any leeched ions are retained and redeposited onto the primary particles (and hence also inside the secondary particles) and that during the final heat treatment step solid-state diffusion processes restore the original composition.

A comparison of the different morphologies of original (compact) particles and nanostructured, open-porous particles is given in Figure 1. As an intermediate product, the spraydried particles before calcination are presented in $1 \mathrm{~b}$ and $1 \mathrm{e}$. It becomes apparent that the particle morphology is severely changed by the milling process, but also that the recrystallization process during calcination is very effective ( $1 \mathrm{c}$ and $1 \mathrm{f}$ ). In the first instance, the purpose of heat treatment is to increase the mechanical stability of the granules by creating cross-links between the primary particles. Of similar importance for the ionic conductivity is that defects stemming from the milling treatment are healed. In the course of the heat treatment, the primary particle size increases above $300 \mathrm{~nm}$.

In Table 3, main properties of NCM-O and NCM-P are listed. While the primary particle size of NCM-P is visibly smaller than that of NCM-O, the secondary particles are of similar size (see also Figure $1 \mathrm{a}, \mathrm{c}$ ). By means of $\mathrm{Hg}$-intrusion porosimetry, about $44 \%$ open porosity with an average pore size of approx. $300 \mathrm{~nm}$ was detected for NCM-P; in the case of NCM-O, no open porosity was detectable. However, by comparing the density measurement from helium pycnometry of both materials an inaccessible average porosity of approx. $4-5 \%$ can be derived for the NCM-O, which is in accordance with SEM investigations of particle cross-sections that are presented in the following chapter. Because of the reduced primary particle size and open porosity, the SSA is nearly one order of magnitude higher for NCM-P. The high porosity of the NCM-P secondary particles is also responsible for the low tap density of $1.4 \mathrm{~g} / \mathrm{cm}^{3}$ compared to $2.4 \mathrm{~g} / \mathrm{cm}^{3}$ of NCM-O.

3.2. Electrode Properties. Although being a basic prerequisite, a detailed inspection of the particle properties is not sufficient to understand the impact of the modified particle design on cell performance. One has also to consider how properties of the electrode layer such as porosity, resistivity, and adhesion strength are determined by the morphology of the active material and the distribution of binders and conductive additives.

3.2.1. Porosity and Microstructure. After coating and inline drying, electrodes of both cathode materials differ clearly in porosity. In electrodes made of dense NCM-O, porosity accounts for 50-55\%, calculated from areal mass loading and thickness. Much higher porosities in the range of 65 to $70 \%$ are found for the porous NCM-P cathodes. To gain more detailed insight into the pore structure, mercury intrusion porosimetry was also applied for characterizing the electrodes, as this method is capable of delivering valuable information about pore size distribution and calendering influence. ${ }^{24,25}$ Figure 2 displays the pore size distribution before and after calendering of electrodes prepared with NCM-O and NCM-P. The denoted overall porosity is also calculated geometrically. The electrodes made of the bulk NCM-O are dominated by pores at around $2 \mu \mathrm{m}$ with additional porosity ranging down to 100 $\mathrm{nm}$. Calendering reduces primarily larger pores, while finer pores, which are related to carbon black and graphite particles, are only slightly affected.

For the uncalendered NCM-P cathode, two clearly separated pore populations are observed. One at around $2 \mu \mathrm{m}$ diameter corresponds to the size of voids, similar to NCM-O. Even moderate calendering reduces the size of these pores very effectively and shifts the distribution to smaller diameters (46\% plot). Enforced calendering to a porosity of $41 \%$ virtually eliminates these pores. Another prominent pore fraction exists slightly below $200 \mathrm{~nm}$ diameter and can be attributed to the inner porosity of the NCM-P secondary particles. The peak maximum shifts only slightly from 170 via 165 to $160 \mathrm{~nm}$ diameter by intensified calendering, while the pore volume below $100 \mathrm{~nm}$ increases for the $41 \%$-porosity electrode. It should be noted that the pore size of the inner porosity is smaller than that observed for the bare NCM-P particles (Table 3). This is probably due to carbon black accumulations around the NCM-P secondary particles, which act as a bottleneck for mercury intrusion. 

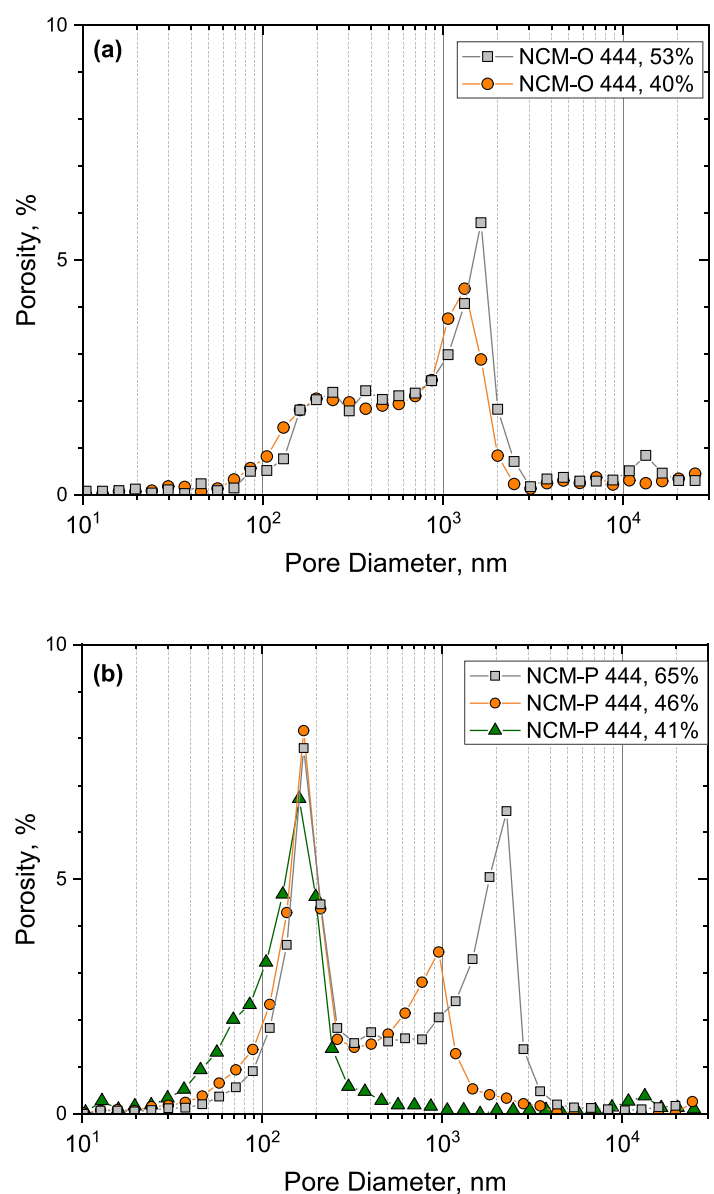

Figure 2. Pore size distribution dependening on the degree of calendering (residual porosity) for (a) NCM-O, uncalendered $=53 \%$ porosity, and (b) NCM-P, uncalendered $=65 \%$ porosity.

Cross-sections of the calendered electrodes help to understand the porosimetry results. Ion-milling allows a virtually artifact-free sample preparation without altering the pore structure. Figure 3 presents the corresponding cross-sections of NCM-O and NCM-P containing electrodes. The ratio of active and inactive components is identical, as well as the aimed porosity of approximately $40-45 \%$. Despite equal compositional settings, obvious microstructural differences result from the altered particle morphology.

The cross-section of the NCM-O 444 electrode shows dense active material particles embedded in a sponge-like carbon black/graphite/binder matrix. Voids of several microns are visible around the active material particles. Figure $3 c$ shows how calendering embosses the hard NCM-O particles partly into the aluminum current collector foil. Although the majority of NMC-O particles are dense, in particular, the largest particles reveal a core with substantial, but presumably closed porosity.

The cross-section of NCM-P 444 is dominated by the porous secondary particles, which are substantially more connected, not least because of pronounced plastic deformation that occurred during calendering treatment (Figure 3d); despite the severe deformation, the secondary particles show no fragmentation. It should be noted that the deformed secondary particles establish a continuous porous network from the electrode surface to the current collector. The tendency to plastic deformation correlates with the primary particle size, as can be derived from the higher magnification image (Figure 3d). Granules consisting of finer primary particles are more readily deformed than their coarse neighbors. The most likely reason for different primary particle sizes among the spherical granules is an inhomogeneous temperature profile within the calcination furnace. Consequently, grain-growth and sinter-neck formation in hotter areas are more pronounced, resulting in granules that are more rigid.

In calendered NCM-P electrodes, the additive matrix fills the space between active material particles homogenously; only a small fraction of the electrode porosity originates from here. Both the matrix compaction and the deformation of the finergrained secondary particles explain why mercury intrusion porosimetry documents an increase of porosity below $100 \mathrm{~nm}$ while simultaneously the total porosity decreases.

3.2.2. Adhesion Strength and Resistivity. Electrode layers with NCM-O exhibit adhesion strength values around $35 \mathrm{~N} /$ $\mathrm{m}$, which is sufficient for any further operations such as winding to coils or die cutting. As shown in Figure 4a, calendering and porosity reduction do not change the adhesion strength notably. For the NCM-P electrodes with an identical binder amount (NCM-P 444), adhesion strength is drastically reduced below $10 \mathrm{~N} / \mathrm{m}$ for the highly porous uncalendered state. Reducing the porosity from $65 \%$ down to $35 \%$ improves adhesion strength only slightly above $10 \mathrm{~N} / \mathrm{m}$. Despite different adhesion strength values for NCM-O 444 and NCM-P 444 electrodes, we observed a very similar failure behavior (see Supporting Information Figure S2). Although predominantly adhesive failure is observed in both cases, significant amounts of electrode components still adhere to the current collector foil indicating locally also cohesive failure.

During slurry preparation, substantial portions of NMPdissolved PVDF binder penetrate the pore network of the secondary particles and remain there after drying. This binder fraction does not contribute to the cohesion within the electrode layer or adhesion to the current collector foil. To compensate the loss of effective binder, additional experiments with increased PVDF concentration were performed (6 instead of 4 parts, NCM-P 446). Thereby, the adhesion strength rises approximately by a factor of two. Porosity reduction via calendering further improves the adhesion strength of the NCM-P, 446 electrodes clearly.

The occurrence of binder transportation into the pore network of the nanostructured secondary particles has been confirmed by energy-dispersive X-ray spectroscopy (EDS) analysis of electrode cross-sections (see Supporting Information Figures S3,S4 and Tables S2,S3). Although the detection of fluorine (from the PVDF binder) in the presence of Mn and Co is difficult because of overlapping peaks, it was possible to detect certainly substantial amounts of $\mathrm{F}$ and $\mathrm{C}$ inside the porous NCM-P particles. On the one hand, binder trapping poses problems for the electrode adhesion to the $\mathrm{Al}$-foil because of the reduction of binder in the additive matrix surrounding the secondary particles. On the other hand, the same effect stabilizes the weakly sintered primary particle network during calendaring. The interior binder phase yields plastic deformation that prevents the formation of large cracks and disintegration of secondary particles during compaction.

The electrical conductivity of the electrodes is determined by the intrinsic conductivity of the active material and by the distribution of the inactive components, in particular, the conductive additives. Measuring the cathode resistivity in through-plane direction gives additional information about the 

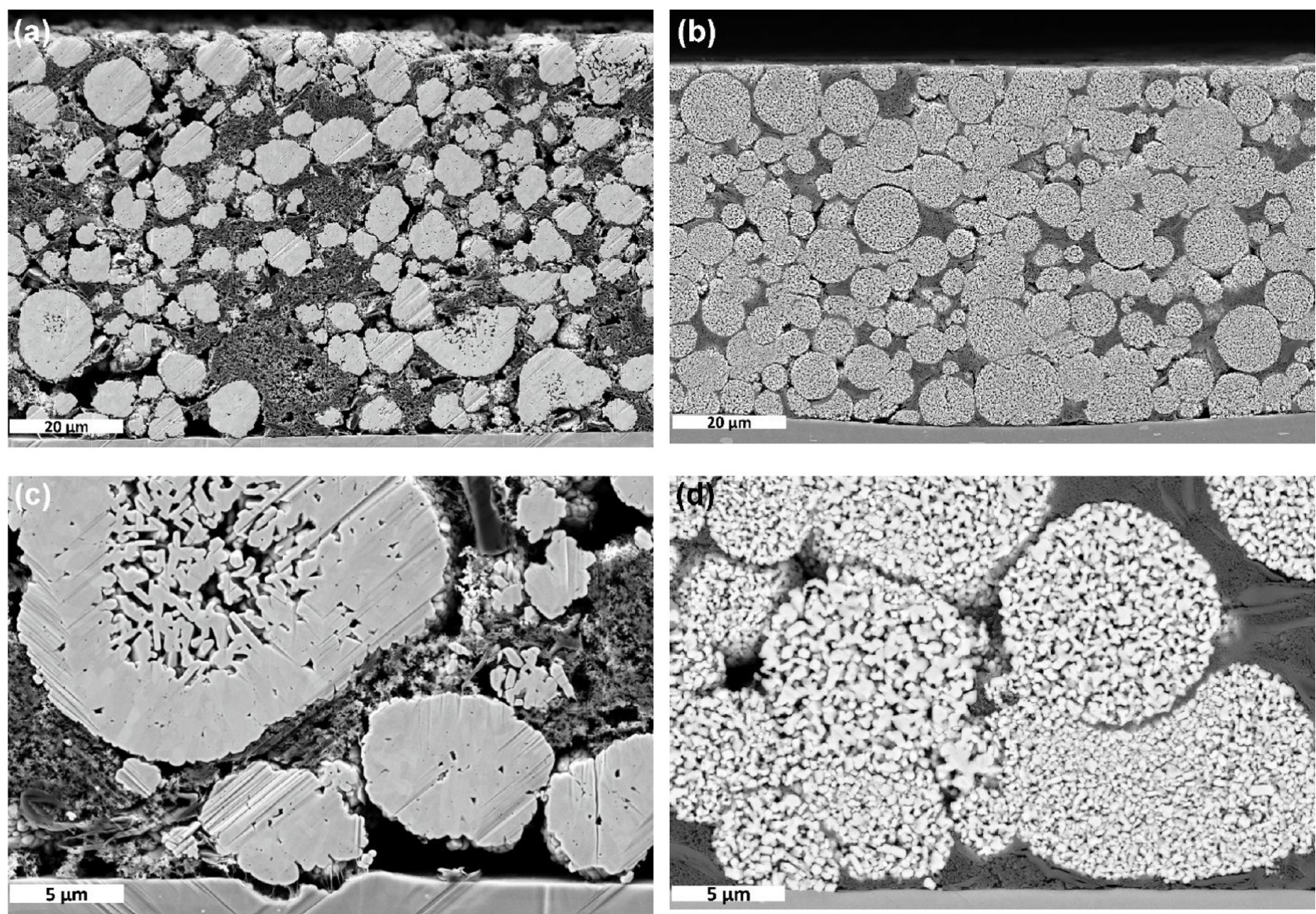

Figure 3. SEM images of ion-milled cross-sections of calendered electrodes $(\sim 40 \%$ porosity) of NCM-O $444(a+c)$ and NCM-P $444(b+d)$.
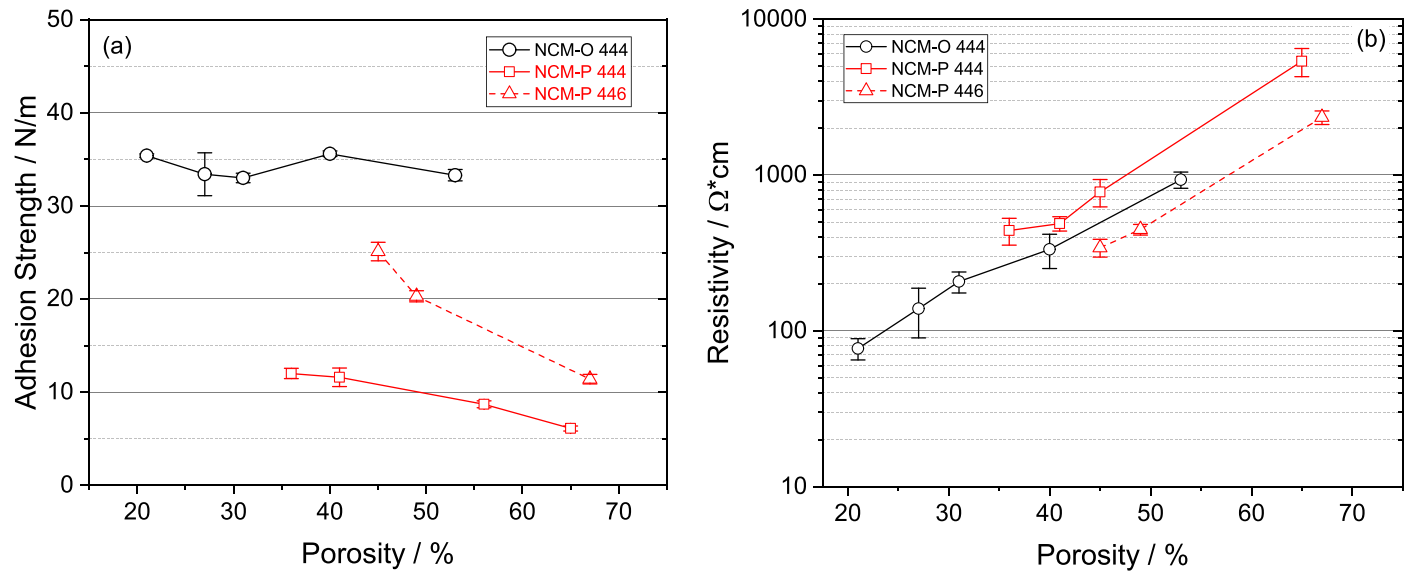

Figure 4. Adhesion strength (a) and resistivity (b) depending on residual porosity after calendering for NCM-O and NCM-P electrodes with standard composition (444) and with increased binder content (446).

contact of the electrode and current collector. ${ }^{26}$ Although a simple correlation between electrode resistance and electrochemical performance does not exist, it is an obvious fact that high resistivities would inhibit adequate cell performance. In Figure $4 \mathrm{~b}$, the development of electrode resistivity presents a clear trend: resistivity decreases with increasing calendering intensity (decreasing residual porosity). It is generally accepted that by calendaring the number of contact points in the electrode increases promoting the electron transport to the active materials. ${ }^{27}$ Uncalendered samples of NCM-P with porosities around $65 \%$ offer a quite high resistivity of more than $4000 \Omega \mathrm{cm}$, while uncalendered NCM-O samples show resistivities of less than $1000 \Omega \mathrm{cm}$ because of their lower initial porosity. When comparing identical porosities, the NCM-P 444 samples still show slightly higher resistances than the NCM-O samples. By recalling the adhesion strength values of the different cathodes, it seems likely that low adhesion corresponds to a weak electrical contact to the current collector. Although the binder itself is nonconductive and has to be enriched with conductive additives, a sufficient 
amount of binder is mandatory to avoid insulating gaps between the electrode layer and current collector. Furthermore, the rigid NCM-O particles locally deform the aluminum current collector foil and increase thereby the contact area (see also Figure $3 \mathrm{c}$ ).

These considerations can explain the lower resistivities of NCM-O 444 and NCM-P 446 compared to NCM-P 444. However, adhesion strength alone is not responsible for the relatively low resistivity of NCM-P 446, especially in comparison to the high adhesive NCM-O 444 sample. The state of the matrix surrounding the active material particles plays also an important role. For the same total amount of porosity, the additive matrix in NCM-P 444 and NCM-P 446 electrode layers shows higher densification as the main porosity is located within the secondary particles. In NCMO electrodes, we have the opposite case, and porosity is limited to the matrix. The combination of sufficient current collector adhesion and high matrix densification finally results in relatively low electrode resistivity of NCM-P 446.

3.3. Cell Tests. 3.3.1. C-Rate Capability. Cell tests at varying $\mathrm{C}$-rates can deliver information about kinetic limitations, which determine the cell performance. To emphasize the differences resulting from the microstructural modifications, identical C-rates were chosen for charge and

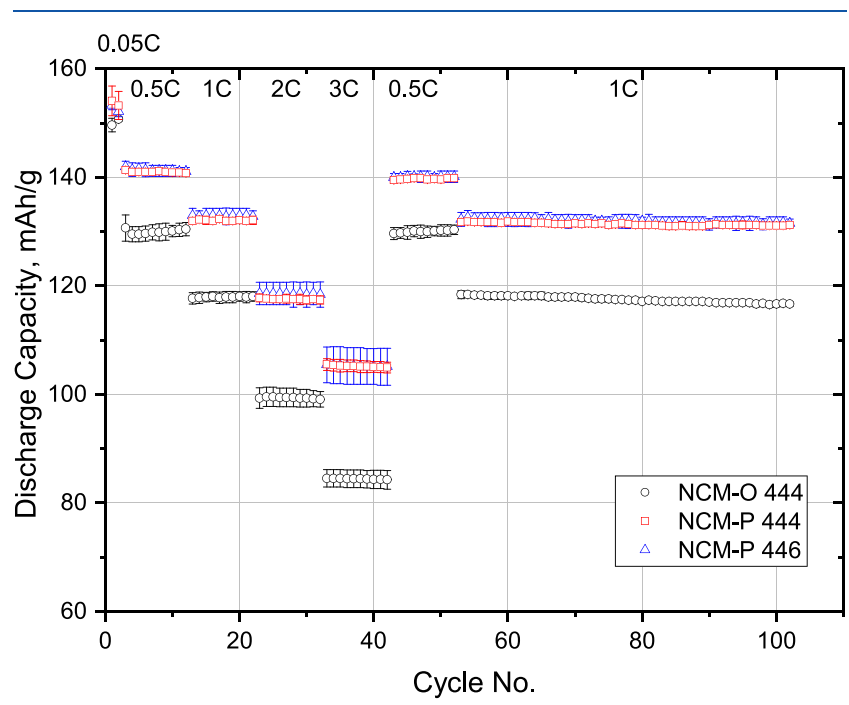

Figure 5. Specific discharge capacities of full-cells at varying C-rates (symmetrical charge and discharge); comparison of original and nanostructured cathode materials (four or six fractions of PVDF binder).

discharge (symmetrical cycling), even though the capacity drop with increasing C-rate is more pronounced in this case. Figure 5 shows that cells with nanostructured cathodes deliver considerably higher discharge capacities compared to the bulk original material. At 3C, this difference amounts to more than $20 \mathrm{mAh} / \mathrm{g}$. Subsequent cycles at $0.5 \mathrm{C}$ are intended to identify possible early degradation processes. Both types (NCM-O and NCM-P) recover completely after 40 cycles, reaching the previous $0.5 \mathrm{C}$ capacities. Furthermore, the additional amount of PVDF binder in NCM-P 446 seems not to affect the rate capability negatively - we just had to take note of an increased scattering of the capacity data.

In Figure 6, the charge/discharge voltage profiles for $0.05 \mathrm{C}$, $1 \mathrm{C}$, and 3C are plotted for NCM-O 444 and NCM-P 444 cells. The superior rate capability of the nanostructured material is

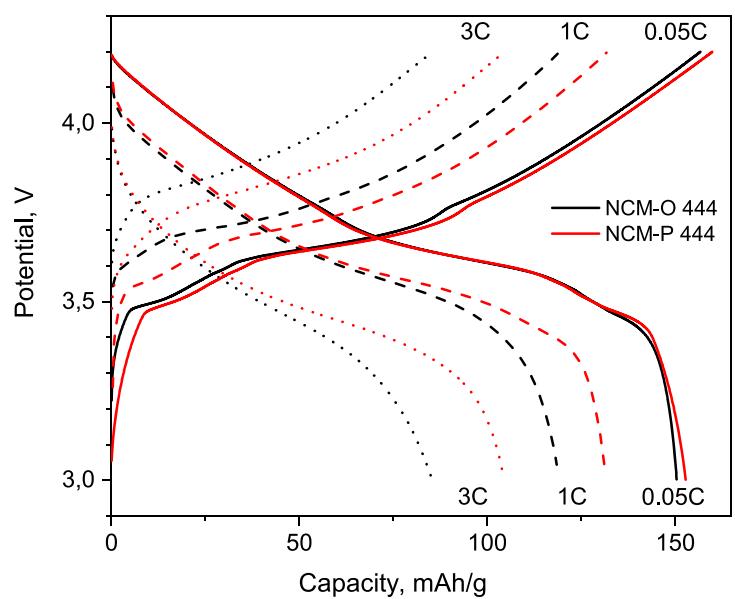

Figure 6. Charge/discharge profiles vs capacity at different C-rates; representative cells with original NCM and nanostructured NCM, both with 444 electrode formulation.

reflected by a favorable potential increase during charging. Especially in the low voltage regime, NCM-P cells display less inclined potential curves. Therefore, more energy can be stored until the upper voltage limit of $4.2 \mathrm{~V}$ is reached, even when potential curves of both materials appear similar in the higher voltage regime.

One could presume that low C-rates should level the kinetic advantages connected to the smaller primary particle size, but the benefit of the porous, nanostructured cathode material is also apparent at $0.05 \mathrm{C}$, which deserves a closer inspection. At very low C-rates, reduced diffusion pathways are expected to be of minor importance. To our understanding, the significantly higher surface area of the porous, nanostructured material should dominate the electrochemistry. At the beginning of the charging step, surface-near delithiation takes place. Here for NCM-P, more $\mathrm{Li}$ is accessible compared to the bulk material, and correspondingly, the potential does not increase as much to achieve a certain state-of-charge. Lu et al. ${ }^{27}$ argued in their paper correspondingly that the lower SSA of larger particles results in an increased activation overpotential at the particle/electrolyte interface.

In the following of this initial effect, $\mathrm{Li}$ solid-state diffusion from inner-particle regions determines the further charging curve progression. The parallel charging curves of both materials suggest comparable diffusion coefficients. From this, it can be concluded that diverging rate capabilities of the two cathode materials result from the influence of the particle morphology on the charging behavior. At high C-rates, short solid-state diffusion pathways are the main advantage of nanostructured active materials. At low C-rates, it is the higher SSA with reduced phase transfer resistance that contributes to a superior capacity.

3.3.2. Capacity Retention. In addition to rate capability, capacity retention during long-term cycling is a decisive factor for the evaluation of cathode materials. For these tests, cells were cycled mainly in CCCV mode with $2 \mathrm{C}$ charge rate and 3C discharge rate. 100 cycles of CCCV mode are separated by 10 cycles with $1 \mathrm{C}(\mathrm{CC})$ during which the data for deriving IC curves are captured. In Figure 7, the trend of discharge capacity up to 1100 cycles in total is plotted for the original and the nanostructured material. It becomes apparent that NCM-P (444, as well as 446) is less affected by degradation and aging than NCM-O. The increasing scattering of the NCM-O cell 


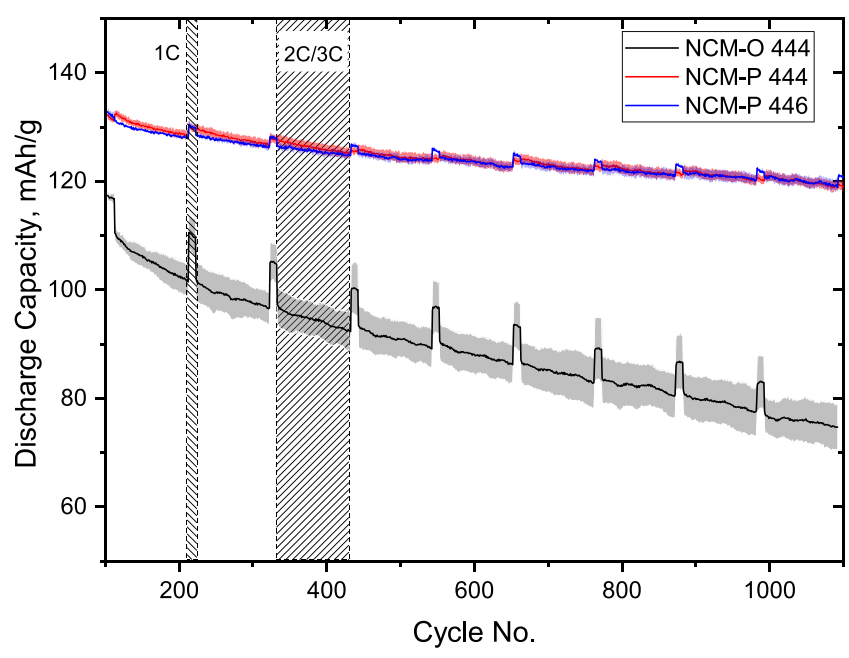

Figure 7. Specific discharge capacities during long-term cycling; 10 cycles at $1 \mathrm{C}(\mathrm{CC})$ are followed by 100 cycles at $2 \mathrm{C} / 3 \mathrm{C}(\mathrm{CCCV})$; comparison of original and nanostructured cathode materials (four and six fractions of PVDF binder); shaded areas represent the degree of data scattering.

capacities suggests also that the corresponding degradation mechanisms are affecting the cell performance unequally.

In Figure $8 \mathrm{a}, \mathrm{b}$, potential curves of representative NCM-O 444 and NCM-P 444 cells during the intermittent 1C cycles are plotted for every 110 cycles. In particular during the first
200 cycles, a pronounced shift of the charging curve to higher potentials is observed for the bulk NCM-O material. The upper voltage limit of $4.2 \mathrm{~V}$ therefore is reached at lower capacities. In contrast, the nanostructured NCM-P reveals very stable charging curves up to 1000 cycles. Only a slight potential increase during cycling takes place above $3.8 \mathrm{~V}$.

To obtain more information about the performance loss and to perform a better analysis of the aging mechanisms, IC curves are preferable ${ }^{28,29}$ In $\mathrm{dQ} / \mathrm{dV}$ versus potential plots, peaks correspond to plateau regions in the charge/discharge curves and represent phase changes in electrodes. The area under the peaks is equivalent to the capacity associated with this phase change, while peak shifts refer to certain capacity fading mechanisms. ${ }^{30}$ Loss of lithium inventory, loss of active material (both on anode and cathode sides), and resistance increase are considered as decisive factors and origin of battery aging phenomena. $^{31}$

Figure $8 \mathrm{c}, \mathrm{d}$ present the corresponding $\mathrm{dQ} / \mathrm{dV}$ plots derived from the potential curves of Figure $8 \mathrm{a}, \mathrm{b}$, demonstrating explicitly the different aging behavior of NCM-O 444 and NVM-P 444 cells. Although the exact position of the peaks depends on the chosen C-rate, the observed peaks can be assigned to certain phase changes. During charging, two main peaks are distinguishable. $\mathrm{Li}$ intercalation at the negative graphite electrode is responsible for the peak between 3.5 and $3.6 \mathrm{~V}$, while the second peak at $3.7 \mathrm{~V}$ is dominated by the $\mathrm{Ni}^{2+}$ $\mathrm{Ni}^{3+}-\mathrm{Ni}^{4+}$ transition at the positive electrode. ${ }^{30,32}$ At about 3.8 $\mathrm{V}$, a shoulder is visible as a third characteristic feature of the IC
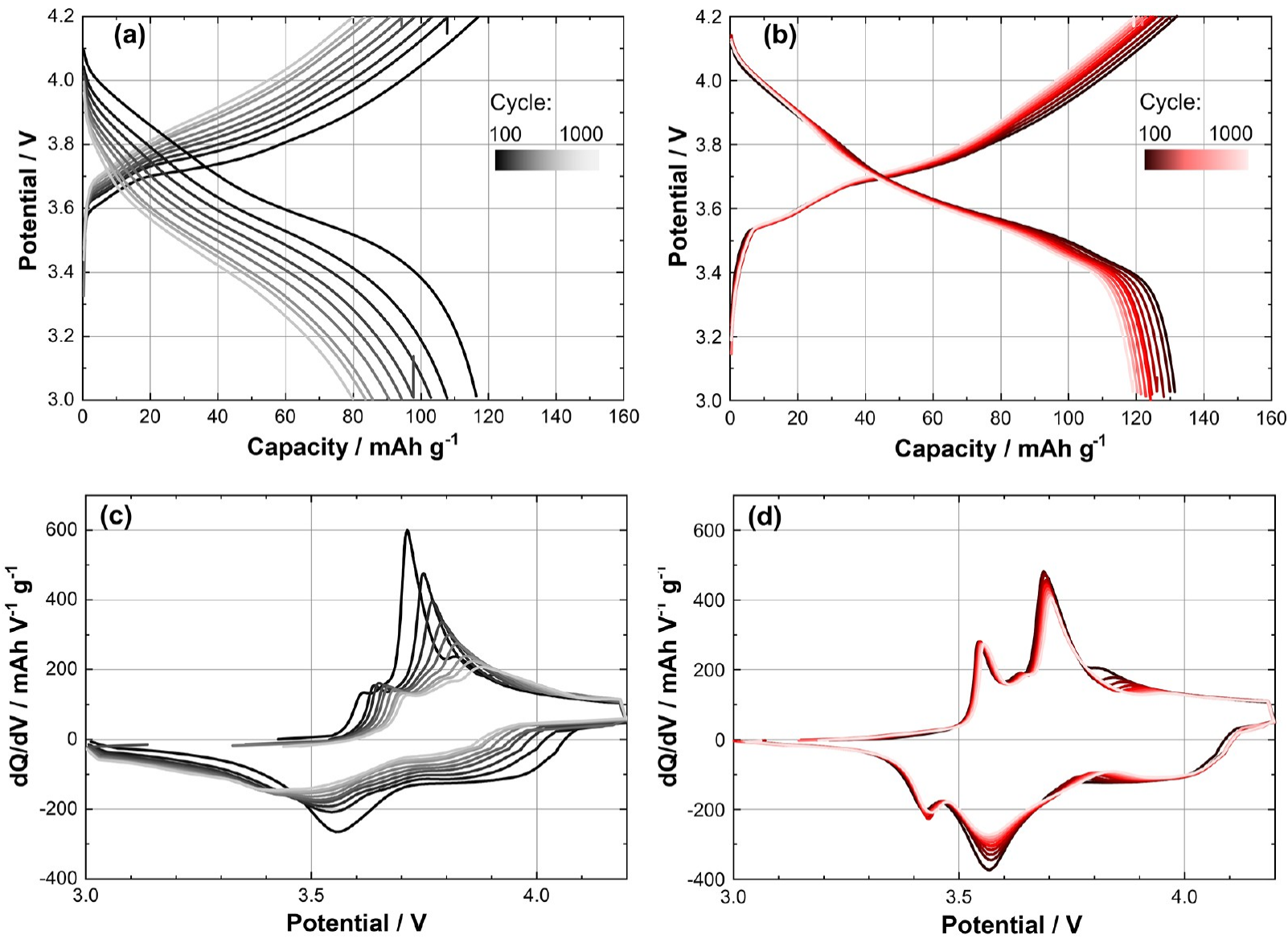

Figure 8. Development of potential curves (1C charge and discharge) with increasing cycle number, (a) NCM-O 444, (b) NCM-P 444; corresponding incremental capacities (c) NCM-O, and (d) NCM-P. 

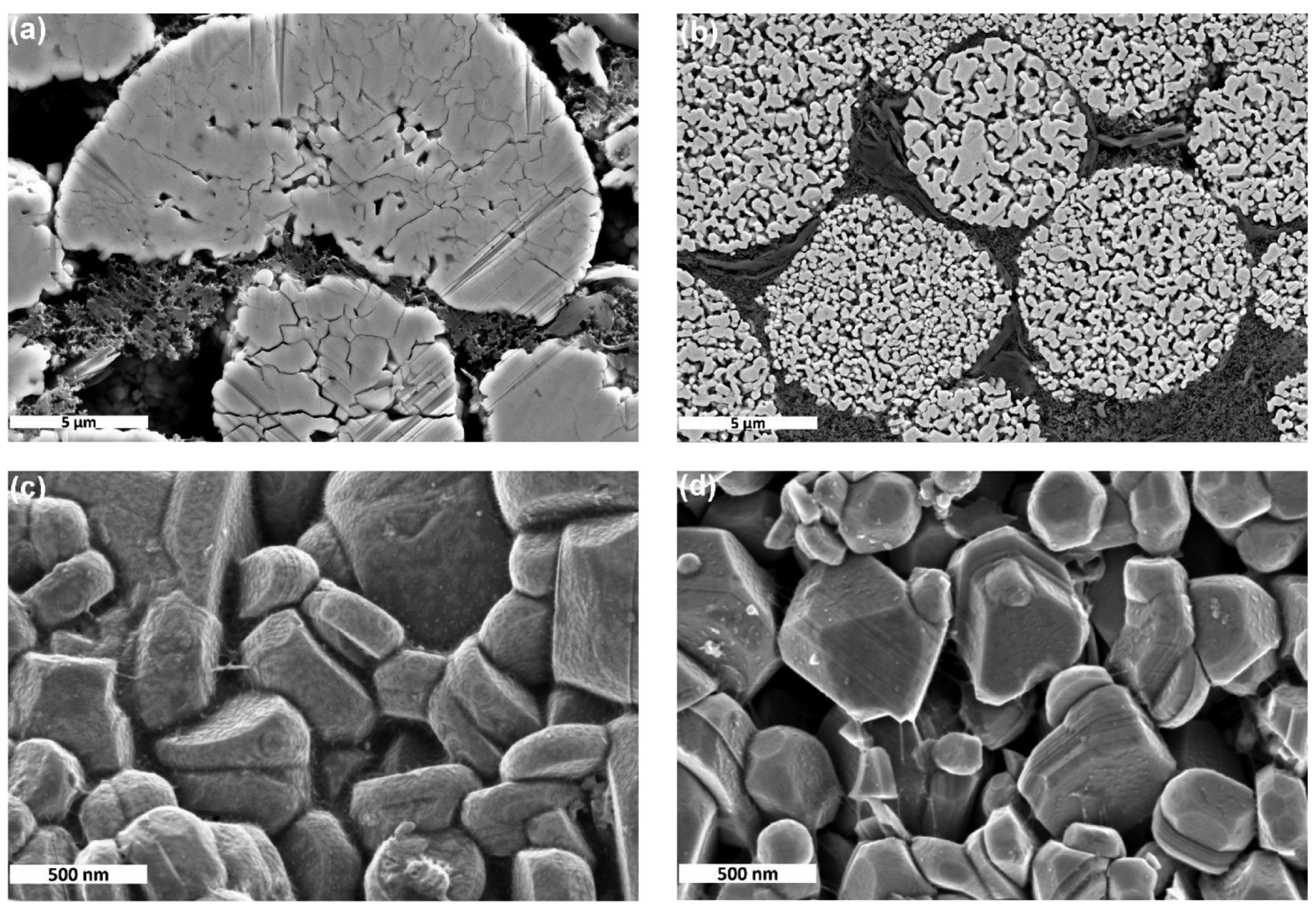

Figure 9. SEM micrographs of electrode cross-sections after 1100 cycles and inspections of corresponding particle surfaces; NCM-O $444(\mathrm{a}+\mathrm{c})$ and NCM-P $444(b+d)$.

curves; according to $\mathrm{Li}$ et al., ${ }^{30}$ the area under this region is associated with changes of the lithium inventory. The strong capacity loss with increasing cycle number of the NCM-O cells is reflected by a strong shift of the positive electrode peak during charging to higher potentials, which is accompanied by a significant decrease of the peak area in Figure 8c. Structural changes such as particle fragmentation reduce the amount of available active material by particle isolation (reduced primary particle connectivity). ${ }^{18}$ The corresponding peak shift to lower potentials during discharge represents the growing polarization. Figure $8 \mathrm{~d}$ clearly proves the different aging behavior of NCM-P compared to NCM-O cells. Both charging peaks nearly do not change their size and position with prolonged cycling. For discharge, the peak intensity at $3.7 \mathrm{~V}$ decreases gradually-as the capacities do. At the same time, and therefore probably connected, the shoulder around $3.8 \mathrm{~V}$ vanishes. This observation could be explained by a loss of lithium inventory on the anode side because of growing solid electrolyte interphase layers. Hence, in contrast to NCM-O, the aging of NCM-P cells is not primarily a cathode effect.

Postmortem SEM investigation of the cycled NCM-O 444 and NCM-P 444 cathodes supports the above considerations. The cracks shown in Figure 9a are supposed to reduce the electronic and ionic conductivity, ${ }^{18}$ which is suited to explain the observed degradation of NCM-O. On the other hand, no particle fracture can be detected for the porous NCM-P (Figure 9b). Inspection of particles from the separator-facing electrode surface reveals further differences between the two materials. Figure 9c,d present high magnification views on the particle surfaces after cycling and carefully washing with DMC. Largely a thin layer of binder and potentially electrolyte decomposition products cover the surface of NCM-O particles (Figure 9c). It is described by Quian et al. ${ }^{33}$ that on the surface of cycled NCM111 cells cathode electrolyte interface (CEI) layers of several $\mathrm{nm}$ thickness can be found and that the thickness of these layers negatively affects the electrochemical performance. In contrast to NCM-O, NCM-P particles expose rather clean surfaces (Figure 9d). Only minor amounts of binder and decomposition products are visible. This observation can be explained by differences in the SSA of NCM-O and NCM-P. The amount of available binder is identical in both cases, but for NCM-P the binder is distributed over an eightfold larger surface area. Furthermore, NCM-P's higher surface area accounts for a reduced areal current density during Li-ion exchange and charge transfer. We suppose that thereby fewer side reactions including electrolyte decomposition occur, resulting in a thinner CEI with less effect on the electrochemical performance.

\section{CONCLUSIONS AND OUTLOOK}

Compared to dense active materials, the particle structure of nanostructured NCM promises a number of advantages for energy storage applications such as short solid-state diffusion and facilitated charge transfer. The effect of varying primary and secondary particle sizes of NCM-P on the electrochemical 
performance-which was not the scope of the present workcan be found in a recent publication. ${ }^{34}$

In principle, the internal porosity of the nanostructured material initially causes a reduction of the volumetric energy density and results in an unfavorable binder distribution and adhesion loss of the electrode. However, these inherent restrictions can be compensated by adapted electrode processing, allowing full utilization of the advantages of nanostructured cathode materials. Although pouch cells with NCM-P cathodes of low adhesion strength have proven excellent long-term cycling behavior, for an automated cell manufacturing it is clearly advisable to have safe adhesion properties. Increasing the PVDF binder content in the electrode, here from 4 to 6 parts ( 3.57 to $5.26 \mathrm{wt} \%$ ), slightly reduces the specific energy of the cell but improves the adhesion strength to an acceptable level without deteriorating the electrochemical properties.

The porosity-related reduction of the energy density is not inevitable as the porous secondary particles are tolerant against intense electrode calendering. Caused by the presence of some binder amounts within the secondary particle voids, a stabilization effect is observed, allowing plastic-like deformation of the granules. The pore size distribution of NCM-P electrodes therefore differs fundamentally from conventional electrodes with a dense cathode material, where the packing is limited to the interparticle voids and associated with massive cracking of particles at a high compaction level. As the accessible intraparticle porosity of the nanostructured NCM-P endures calendering, the interparticle porosity with the additive matrix can be compacted vigorously. In contrast to dense particles, the electrolyte can still utilize the intraparticle porosity as a network for $\mathrm{Li}$ - ion transport. With progressing cycling, more advantages of NCM-P become significant. The smaller primary particles in combination with an open porosity accumulate less stresses and consequently prevent fragmentation of the cathode material enabling an improved lifetime of the cells.

The here presented investigations still focus on NMC111 and NMP-based electrode manufacturing. In the meantime, nickel-rich cathode materials are gaining more relevance because of their improved specific capacity. However, these materials suffer from a reduced service life, which is-among other factors-because of a rising tendency for crack formation (secondary particle breakdown) with increasing Ni content. ${ }^{1,35}$ Nanostructuring of these materials has the capability to improve the aging behavior clearly. For environmental and also for cost reasons, aqueous processing of cathodes is becoming increasingly of interest. ${ }^{36,37}$ Because all relevant cathode materials massively interact with water, ${ }^{22}$ the high SSA of the porous and nanostructured cathode materials will be of special relevance. Further questions arise from the different binder architecture that is applied in aqueous processing. These questions are currently under investigation and will be addressed in the following publications.

\section{ASSOCIATED CONTENT}

\section{(s) Supporting Information}

The Supporting Information is available free of charge at https://pubs.acs.org/doi/10.1021/acsaem.0c03187.

Additional figures and tables including XRD patterns, ICP-OES data, SEM images, and EDS data (PDF)

\section{AUTHOR INFORMATION}

\section{Corresponding Author}

Marcus Müller - Institute for Applied Materials IAM-ESS

(Energy Storage Systems), Karlsruhe Institute of Technology, Eggenstein-Leopoldshafen 76344, Germany; @ orcid.org/ 0000-0002-5562-7201; Email: marcus.mueller@kit.edu

\section{Authors}

Luca Schneider - Institute for Applied Materials IAM-ESS (Energy Storage Systems), Karlsruhe Institute of Technology, Eggenstein-Leopoldshafen 76344, Germany

Nicole Bohn - Institute for Applied Materials IAM-ESS (Energy Storage Systems), Karlsruhe Institute of Technology, Eggenstein-Leopoldshafen 76344, Germany

Joachim R. Binder - Institute for Applied Materials IAM-ESS (Energy Storage Systems), Karlsruhe Institute of Technology, Eggenstein-Leopoldshafen 76344, Germany; (1) orcid.org/ 0000-0003-2237-1411

Werner Bauer - Institute for Applied Materials LAM-ESS (Energy Storage Systems), Karlsruhe Institute of Technology, Eggenstein-Leopoldshafen 76344, Germany; (1) orcid.org/ 0000-0002-5923-2426

Complete contact information is available at:

https://pubs.acs.org/10.1021/acsaem.0c03187

\section{Notes}

The authors declare no competing financial interest.

\section{ACKNOWLEDGMENTS}

We want to thank our colleagues Margret Offermann for mercury intrusion porosimetry, particle size distribution, and He-pycnometry measurements, Bianca Ehlert for cell assembling, and Dr. Pirmin Stüble for the XRD measurements. Furthermore, we thank Dr. Thomas Bergfeldt's group at IAMAWP for performing the ICP-OES measurements. The development of the hierarchically structured NCM materials has been supported by the German Federal Ministry for Economic Affairs and Energy (BMWi) and granted through Project Management Jülich (03ET6095A). This work contributes to the research performed at CELEST (Center for Electrochemical Energy Storage Ulm-Karlsruhe).

\section{REFERENCES}

(1) Schipper, F.; Erickson, E. M.; Erk, C.; Shin, J.-Y.; Chesneau, F. F.; Aurbach, D. Review-Recent Advances and Remaining Challenges for Lithium Ion Battery Cathodes. J. Electrochem. Soc. 2017, 164, A6220-A6228.

(2) Myung, S. T.; Maglia, F.; Park, K. J.; Yoon, C. S.; Lamp, P.; Kim, S. J.; Sun, Y. K. Nickel-Rich Layered Cathode Materials for Automotive Lithium-Ion Batteries: Achievements and Perspectives. ACS Energy Lett. 2017, 2, 196-223.

(3) Chen, D.; Kramer, D.; Mönig, R. Chemomechanical Fatigue of LiMn1.95Al0.05O4 Electrodes for Lithium-Ion Batteries. Electrochim. Acta 2018, 259, 939-948.

(4) Hausbrand, R.; Cherkashinin, G.; Ehrenberg, H.; Gröting, M.; Albe, K.; Hess, C.; Jaegermann, W. Fundamental Degradation Mechanisms of Layered Oxide Li-Ion Battery Cathode Materials : Methodology, Insights and Novel Approaches. Mater. Sci. Eng., B 2015, 192, 3-25.

(5) Liu, H.; Wolf, M.; Karki, K.; Yu, Y. S.; Stach, E. A.; Cabana, J.; Chapman, K. W.; Chupas, P. J. Intergranular Cracking as a Major Cause of Long-Term Capacity Fading of Layered Cathodes. Nano Lett. 2017, 17, 3452-3457. 
(6) Sun, G.; Sui, T.; Song, B.; Zheng, H.; Lu, L.; Korsunsky, A. M. On the Fragmentation of Active Material Secondary Particles in Lithium Ion Battery Cathodes Induced by Charge Cycling. Extrem. Mech. Lett. 2016, 9, 449-458.

(7) Kondrakov, A. O.; Schmidt, A.; Xu, J.; Geßwein, H.; Mönig, R.; Hartmann, P.; Sommer, H.; Brezesinski, T.; Janek, J. Anisotropic Lattice Strain and Mechanical Degradation of High- and Low-Nickel NCM Cathode Materials for Li-Ion Batteries. J. Phys. Chem. C 2017, 121, 3286-3294.

(8) Kim, U. H.; Lee, E. J.; Yoon, C. S.; Myung, S. T.; Sun, Y. K. Compositionally Graded Cathode Material with Long-Term Cycling Stability for Electric Vehicles Application. Adv. Energy Mater. 2016, 6, $1-8$.

(9) Birkl, C. R.; Roberts, M. R.; Mcturk, E.; Bruce, P. G.; Howey, D. A. Degradation Diagnostics for Lithium Ion Cells. J. Power Sources 2017, 341, 373-386.

(10) Yan, P.; Zheng, J.; Gu, M.; Xiao, J.; Zhang, J.; Wang, C. Intragranular Cracking as a Critical Barrier for High-Voltage Usage of Layer-Structured Cathode for Lithium-Ion Batteries. Nat. Commun. 2017, 8, 1-9.

(11) Zhang, Y.; Zhao, C.; Guo, Z. Simulation of Crack Behavior of Secondary Particles in Li-Ion Battery Electrodes during Lithiation/deLithiation Cycles. Int. J. Mech. Sci. 2019, 155, 178-186.

(12) Cabelguen, P.-E.; Peralta, D.; Cugnet, M.; Maillet, P. Impact of Morphological Changes of LiNi1/3Mn1/3Co1/3O2on Lithium-Ion Cathode Performances. J. Power Sources 2017, 346, 13-23.

(13) Chen, Z.; Wang, J.; Chao, D.; Baikie, T.; Bai, L.; Chen, S.; Zhao, Y.; Sum, T. C.; Lin, J.; Shen, Z. Hierarchical Porous LiNil/3 Co1/3 Mn1/3 O2 Nano-/Micro Spherical Cathode Material: Minimized Cation Mixing and Improved Li + Mobility for Enhanced Electrochemical Performance. Sci. Rep. 2016, 6, 1-10.

(14) Li, L.; Wang, L.; Zhang, X.; Xie, M.; Wu, F.; Chen, R. Structural and Electrochemical Study of Hierarchical LiNi1/3Co1/3Mn1/3O2 Cathode Material for Lithium-Ion Batteries. ACS Appl. Mater. Interfaces 2015, 7, 21939-21947.

(15) Lin, F.; Nordlund, D.; Li, Y.; Quan, M. K.; Cheng, L.; Weng, T. C.; Liu, Y.; Xin, H. L.; Doeff, M. M. Metal Segregation in Hierarchically Structured Cathode Materials for High-Energy Lithium Batteries. Nat. Energy 2016, 1, 1-8.

(16) Yang, Z.; Lu, J.; Bian, D.; Zhang, W.; Yang, X.; Xia, J.; Chen, G.; Gu, H.; Ma, G. Stepwise Co-Precipitation to Synthesize LiNil/ 3Co1/3Mn1/3O2one-Dimensional Hierarchical Structure for Lithium Ion Batteries. J. Power Sources 2014, 272, 144-151.

(17) Oljaca, M.; Blizanac, B.; Du Pasquier, A.; Sun, Y.; Bontchev, R.; Suszko, A.; Wall, R.; Koehlert, K. Novel Li(Ni1/3Co1/3Mn1/3)O2 Cathode Morphologies for High Power Li-Ion Batteries. J. Power Sources 2014, 248, 729-738.

(18) Dreizler, A. M.; Bohn, N.; Geßwein, H.; Müller, M.; Binder, J. R.; Wagner, N.; Friedrich, K. A. Investigation of the Influence of Nanostructured $\mathrm{LiNi}_{0.33} \mathrm{Co}_{0.33} \mathrm{Mn}_{0.33} \mathrm{O}_{2}$ Lithium-Ion Battery Electrodes on Performance and Aging. J. Electrochem. Soc. 2018, 165, A273-A282.

(19) Bockholt, H.; Indrikova, M.; Netz, A.; Golks, F.; Kwade, A. The Interaction of Consecutive Process Steps in the Manufacturing of Lithium-Ion Battery Electrodes with Regard to Structural and Electrochemical Properties. J. Power Sources 2016, 325, 140-151.

(20) Hawley, W. B.; Parejiya, A.; Bai, Y.; Meyer, H. M.; Wood, D. L.; Li, J. Lithium and Transition Metal Dissolution Due to Aqueous Processing in Lithium-Ion Battery Cathode Active Materials. J. Power Sources 2020, 466, 228315.

(21) Wood, M.; Li, J.; Ruther, R. E.; Du, Z.; Self, E. C.; Meyer, H. M.; Daniel, C.; Belharouak, I.; Wood, D. L. Chemical Stability and Long-Term Cell Performance of Low-Cobalt, Ni-Rich Cathodes Prepared by Aqueous Processing for High-Energy Li-Ion Batteries. Energy Storage Mater. 2020, 24, 188-197.

(22) Bauer, W.; Çetinel, F. A.; Müller, M.; Kaufmann, U. Effects of $\mathrm{PH}$ Control by Acid Addition at the Aqueous Processing of Cathodes for Lithium Ion Batteries. Electrochim. Acta 2019, 317, 112-119.
(23) Loeffler, N.; Kim, G. T.; Mueller, F.; Diemant, T.; Kim, J. K.; Behm, R. J.; Passerini, S. In Situ Coating of Li[Ni0.33Mn0.33Co0.33]O2 Particles to Enable Aqueous Electrode Processing. ChemSusChem 2016, 9, 1112-1117.

(24) Meyer, C.; Bockholt, H.; Haselrieder, W.; Kwade, A. Characterization of the Calendering Process for Compaction of Electrodes for Lithium-Ion Batteries. J. Mater. Process. Technol. 2017, $249,172$.

(25) Froboese, L.; Titscher, P.; Westphal, B.; Haselrieder, W.; Kwade, A. Mercury Intrusion for Ion- and Conversion-Based Battery Electrodes - Structure and Diffusion Coefficient Determination. Mater. Charact. 2017, 133, 102-111.

(26) Westphal, B. G.; Mainusch, N.; Meyer, C.; Haselrieder, W.; Indrikova, M.; Titscher, P.; Bockholt, H.; Viöl, W.; Kwade, A Influence of High Intensive Dry Mixing and Calendering on Relative Electrode Resistivity Determined via an Advanced Two Point Approach. J. Energy Storage 2017, 11, 76-85.

(27) Lu, X.; Daemi, S. R.; Bertei, A.; Kok, M. D. R.; O’Regan, K. B.; Rasha, L.; Park, J.; Hinds, G.; Kendrick, E.; Brett, D. J. L.; Shearing, P. R. Microstructural Evolution of Battery Electrodes During Calendering. Joule 2020, 4, 2746-2768.

(28) Han, X.; Feng, X.; Ouyang, M.; Lu, L.; Li, J.; Zheng, Y.; Li, Z. A Comparative Study of Charging Voltage Curve Analysis and State of Health Estimation of Lithium-Ion Batteries in Electric Vehicle. Automot. Innov. 2019, 2, 263-275.

(29) Dubarry, M.; Truchot, C.; Liaw, B. Y. Synthesize Battery Degradation Modes via a Diagnostic and Prognostic Model. J. Power Sources 2012, 219, 204-216.

(30) Li, Y.; Abdel-Monem, M.; Gopalakrishnan, R.; Berecibar, M.; Nanini-Maury, E.; Omar, N.; van den Bossche, P.; Van Mierlo, J. A Quick On-Line State of Health Estimation Method for Li-Ion Battery with Incremental Capacity Curves Processed by Gaussian Filter. J. Power Sources 2018, 373, 40-53.

(31) Barré, A.; Deguilhem, B.; Grolleau, S.; Gérard, M.; Suard, F.; Riu, D. A. Review on Lithium-Ion Battery Ageing Mechanisms and Estimations for Automotive Applications. J. Power Sources 2013, 241, 680-689.

(32) Jung, R.; Metzger, M.; Maglia, F.; Stinner, C.; Gasteiger, H. A. Oxygen Release and Its Effect on the Cycling Stability of LiNi x Mn y $\mathrm{Co} \mathrm{z}_{\mathrm{O}} 2$ (NMC) Cathode Materials for Li-Ion Batteries. J. Electrochem. Soc. 2017, 164, A1361-A1377.

(33) Qian, Y.; Niehoff, P.; Börner, M.; Grützke, M.; Mönnighoff, X.; Behrends, P.; Nowak, S.; Winter, M.; Schappacher, F. M. Influence of Electrolyte Additives on the Cathode Electrolyte Interphase (CEI) Formation on $\mathrm{LiNi} 1 / 3 \mathrm{Mn} 1 / 3 \mathrm{Co} 1 / 3 \mathrm{O} 2$ in Half Cells with Li Metal Counter Electrode. J. Power Sources 2016, 329, 31-40.

(34) Wagner, A. C.; Bohn, N.; Geßwein, H.; Neumann, M.; Osenberg, M.; Hilger, A.; Manke, I.; Schmidt, V.; Binder, J. R. Hierarchical Structuring of NMC111-Cathode Materials in LithiumIon Batteries: An In-Depth Study on the Influence of Primary and Secondary Particle Sizes on Electrochemical Performance. ACS Appl. Energy Mater. 2020, 3, 12565-12574.

(35) de Biasi, L.; Schwarz, B.; Brezesinski, T.; Hartmann, P.; Janek, J.; Ehrenberg, H. Chemical, Structural, and Electronic Aspects of Formation and Degradation Behavior on Different Length Scales of Ni-Rich NCM and Li-Rich HE-NCM Cathode Materials in Li-Ion Batteries. Adv. Mater. 2019, 31, 1900985

(36) Bresser, D.; Buchholz, D.; Moretti, A.; Varzi, A.; Passerini, S. Alternative Binders for Sustainable Electrochemical Energy Storagethe Transition to Aqueous Electrode Processing and Bio-Derived Polymers. Energy Environ. Sci. 2018, 11, 3096-3127.

(37) Wood, D. L.; Li, J.; Daniel, C. Prospects for Reducing the Processing Cost of Lithium Ion Batteries. J. Power Sources 2015, 275, 234-242. 